\title{
A PROBLEMÁTICA DO DESEÑO DAS POLÍTICAS DE MITIGACIÓN NO SECTOR
}

AGRARIO

Dionisio RODRÍGUEZ ÁLVAREZ*

Meteogalicia. Consellería de Medio Ambiente, Territorio e Infraestruturas,Santiago de Compostela, dionisio.rodriguez.alvarez@xunta.es

Resumo. A loita contra o cambio climático implica elaborar as políticas e medidas de redución de emisións ou o fomento dos sumidoiros e o sector agrario é un dos sectores económicos para o que hai que establecer políticas de mitigación. O inventario de gases de efecto invernadoiro (GEI) de cada país é un dos documentos chave para o deseño das políticas de mitigación xa que nos permite coñecer as fontes produtoras e a cantidade emitida por cada unha, así como os potenciais de sumidoiro dos cultivos e solos agrarios. Neste traballo, mediante unha análise comparada de diferentes propostas de medidas de mitigación para o sector agrario elaboradas no ámbito europeo, internacional (FAO) ou nacional e outras propostas de países de agricultura avanzada, como Nova Zelanda, amósanse as dificultades de acadar que o deseño desas políticas e medidas sexa efectivo, que se reflicta contablemente no inventario de GEI de cada país e que, ademais, signifique reducións a nivel de explotación agraria. Desenvólvese un exemplo de política de mitigación mediante a análise do subsector leiteiro europeo.

Palabras chave: Sector agrario, Inventario de gases de efecto invernadoiro, Mitigación.

The diversity of problems to design mitigation policies in the agricultural industry

Abstract. Fighting against climate change involves elaborating policies and measures to reduce emissions or the promotion of swage systems and the agricultural industry is one for which it is necessary to establish mitigation policies. The GHG (greenhouse gas) inventory of each country is one of the key documents to design mitigation policies as it allows us to know the production sources and the amount emitted by them, as well as the potential swage of crops and agricultural soils. Through a comparative analysis of different proposals of mitigation measures for the agrarian sector, developed at different levels, European (EU), International (FAO), National (Spain) and other proposals from countries of advanced agriculture, such as New Zealand, this article shows the difficulties to design such policies and measures so they are effective, which reflects accounted impacts in the GHG inventory of each country and that also implies reductions at a farming level. An example of mitigation policy is explained through the analysis of the European dairy subsector.

Keywords : Agriculture, greenhouse gas inventory, mitigation.

Sumario: Introdución e obxectivos. 1. O inventario de Gases de Efecto Invernadoiro e a agricultura. 2. Políticas de mitigación da Unión Europea. 2.1 A folla de Ruta de España. 3. Análise da FAO. 3.1 Subsector leiteiro europeo. 4. Innovacións tecnolóxicas: Nova Zelanda. 5. Conclusións. Bibliografía

\section{Introdución e obxectivos}

A agricultura é un dos sectores económicos que coa súa actividade contribúe a xerar os gases que producen o efecto invernadoiro e polo tanto o cambio climático. Esta actividade económica medida mediante o PIB, no ámbito europeo, só aporta o 1,3\% do PIB europeo e con grandes diferenzas entre os Estados Membro que varían do 0,3\% ao 4,7\%. ${ }^{1}$ Porén, a

\footnotetext{
* Presentación no X Congreso da asociación española de Economía Agraria. Córdoba 9 a 11 de setembro de 2015.

1The Common Agricultural Policy. A partnership between Europe and Farmers. European Commission.
} 
efectos de xeración de gases de efecto invernadoiro a "agricultura" europea xerou, no ano 2012, 469 millóns de t. de $\mathrm{CO}_{2}$ equivalente ao que supón un 10,3\% dos 4.544 millones de t. de $\mathrm{CO}_{2}$-eq que xerou a Unión Europea 27 en todos os sectores. ${ }^{2}$ De forma similar a Europa, as emisións da agricultura para España no ano 2012 foron uns 37 millóns t. de $\mathrm{CO}_{2}$-eq e representaron un $11,07 \%$ das emisións totais españolas de $\mathrm{CO}_{2}$-eq. ${ }^{3}$.

A FAO prognostica que o incremento da demanda de alimentos continuará intensamente nas próximas décadas debido, tanto aos incrementos esperados da poboación mundial, como á mellora da calidade de vida de moitos países en vías de desenvolvemento, que estimularán que esa demanda sexa con esixencias de maior calidade e cun incremento do acceso ao consumo de carne por parte das súas poboacións. Estas previsións implican un incremento das emisións polo que o acerto no deseño das medidas de mitigación será unha das primeiras cuestións a acadar e, posteriormente, como recolle un informe da Unión Europea4, será necesario incrementar o coñecemento e as cualificacións dos actores agrarios, que serán os encargados de poñelas en práctica.

Para acadar ese acerto á hora de deseñar as políticas de mitigación un documento imprescindible é o inventario de GEI, pois nel recóllense as fontes emisoras e as súas cantidades. A elaboración dun inventario de GEI é un proceso complexo para o que é necesario posuír un coñecemento, así como o descoñecemento, que a veces existe, das súas regras contables. Isto fai que a elaboración de medidas de mitigación específicas do sector "agricultura" sexa unha cuestión bastante complicada e necesitada de expertos profesionais multidisciplinares que coñezan en profundidade ademais do sector, esas regras contables que sustentan a súa elaboración. Coñecer a estrutura do inventario de gases de efecto invernadoiro (GEI) e das metodoloxías deseñadas para a medición das emisións/ absorcións de cada un dos focos emisores ou os sumidoiros proporcionaranos o reflexo contable das fontes produtoras e a cantidade emitida por cada unha. A correcta contabilización vainos condicionar fortemente as análises e medidas que de forma específica deseñemos e pretendamos instituír no sector agrario. O presente traballo trata de poñer de relevo, mediante a análise de propostas de organizacións e institucións diversas, a complexidade que supón o deseño das políticas de mitigación no sector agrario á hora de acadar a súa captación polo inventario GEI e amosar a importancia e utilidade de posuír un coñecemento especializado das Directrices $^{5}$ que regulan a elaboración deste documento.

\section{O inventario de Gases de Efecto Invernadoiro e a agricultura}

A primeira cuestión que debemos coñecer é que as emisións de gases de efecto invernadoiro dun un país débense presentar distribuídas en diferentes sectores e clasificadas segundo a seguinte Táboa 1. Para elaborar estes inventarios existen unhas regras aprobadas pola ONU (UNFCCC), as chamadas Directrices, que todos os Estados

\footnotetext{
2 Annual European Union greenhouse gas inventory 1990-2012 and inventory report 2014. EEA (European Environment Agency)

3 España, Informe Inventarios GEI 1990-2012 (Abril de 2014). MAGRAMA

4 DG Climate Action. European Commission. (2012). Next phase of the European Climate Change Programme: Analysis of Member States actions to implement the Effort Sharing Decision and options for further community-wide measures. Agriculture sector - Policy case studies report. AEA DG ENV C.5/ SER/ 2009/ 0037. June 2012. DG Climate Action.

5 International Panel of Climate Change. UNEP.WMO.(1996). Revised 1996 IPCC Guidelines for National Greenhouse Gas Inventories. IPCC.

International Panel of Climate Change. UNEP.WMO (2006) Directrices do IPCC de 2006 para os inventarios nacionais de gases de efecto invernadoiro. IPCC.
} 
deben seguir e estes inventarios son posteriormente revisados por equipos multidisciplinares de especialistas na materia para comprobar a exactitude e veracidade dos datos. Os compromisos internacionais, referendados en Tratados, que se acordan entre as diferentes partes, non servirían de nada se non houbera estas regras comúns. Ata o presente ano os inventarios elaborábanse seguindo as Directrices de 1996 do IPCC6, melloradas con Guías de Boas prácticas, porén, a partir de 2015, presentaranse de acordo ás Directrices de 2006 do IPCC , que tamén están sendo melloradas.

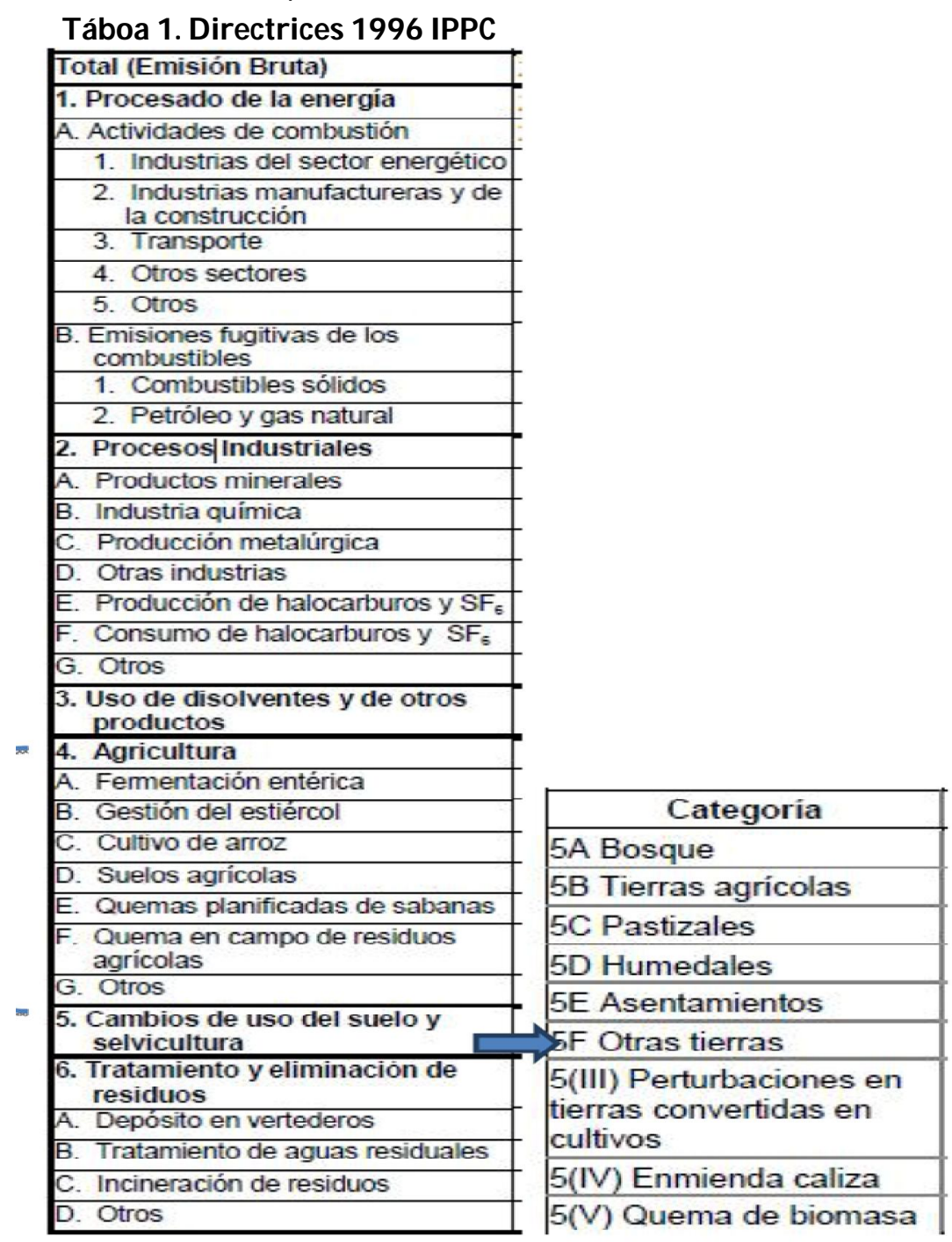

Fonte8:

6 International Panel of Climate Change. UNEP.WMO.(1996). Revised 1996 IPCC Guidelines for National Greenhouse Gas Inventories. IPCC.

7 International Panel of Climate Change. UNEP.WMO (2006) Directrices do IPCC de 2006 para os inventarios nacionais de gases de efecto invernadoiro. IPCC.

8 International Panel of Climate Change. UNEP.WMO.(1996). Revised 1996 IPCC Guidelines for National Greenhouse Gas Inventories. IPCC. 
Unha primeira conclusión, que podemos obter observando a Táboa 1 (Directrices 1996 IPCC), é a complexa clasificación das emisións do que se chama sector agricultura e que se presenta no seu apartado 4. Podemos observar outro apartado, o 5, titulado Cambios do uso do solo e selvicultura, no que nos fala de terras agrícolas, pasteiros, etc. no que tamén se rexistrarán emisións do sector agrario, considerando o sector forestal á parte. A segunda observación é que todas as emisións que teñan que ver co gasto enerxético (emprego de combustibles) na agricultura non serán rexistradas no apartado 4, senón que a norma marca que debe ser rexistrado no Apartado 1 de Procesado da enerxía. Non serán emisións que dende o punto de vista contable pertenzan ao sector agrario. Podemos dicir que, cando nos referimos a emisións do sector agricultura, tomadas do inventario de GEI, non nos estamos refirindo ás emisións do que comúnmente entendemos por "sector agrario". No apartado 4 Agricultura, non se inclúen todas as emisións procedentes do gasto enerxético derivado dos traballos de cultivo (arado, sementeira, recolleita, etc.), nin tampoco as emisións producidas polos diferentes cultivos agrícolas e pasteiros, que tamén poden ser sumidoiros de $\mathrm{CO}_{2}$. Estas emisións non computan nos sete epígrafes en que se divide o apartado 4. É moi importante ter presente esta estrutura do inventario de GEI, pois vainos condicionar fortemente as análises e medidas que de forma específica deseñemos e pretendamos insitituír no sector agrario. E, ademais, necesítase un coñecemento fondo das metodoloxías deseñadas para a medición das emisións/ absorcións de cada un dos epígrafes.

\section{Políticas de mitigación da Unión Europea}

Neste apartado analízase a proposta de medidas de mitigación ou redución de emisións tanto a nivel de explotación agraria como a nivel de estado e descríbese a problemática de que as devanditas medidas sexan captadas polo inventario de GEI, que en definitiva é o documento que reflicte "a contabilidade" das emisións dun país. Co obxectivo de identificar e apoiar as medidas agronómicas que mellor contribúen a loitar contra 0 cambio climático o Parlamento Europeo elaborou un informe titulado "Medidas a nivel de granxa para reducir as emisións de gases de efecto invernadoiro pola agricultura europea"9, e fundamenta a devandita proposta nun proxecto LIFE+10, da Unión Europea, AgriClimateChange que se desenvolveu simultaneamente en 4 países europeos (Francia, Alemaña, Italia e España) entre setembro de 2010 e decembro de 2013.

Un dos resultados do proxecto foi a creación da ferramenta ACCT (AgriClimateChange Tool) para avaliar consumos enerxéticos, emisións de GEI e a almacenaxe de carbono a escala de explotación. Aplicouse esta ferramenta para avaliar máis de 120 explotacións agrícolas ao longo dos 3 anos de proxecto e isto permitiu propoñer diferentes medidas de mitigación. Estudáronse en profundidade nove casos nos catro países e para diferentes explotacións para expoñer os beneficios obtidos coas medidas máis efectivas. As medidas de mitigación propostas co seu nivel de priorización podémolas observar na seguinte Táboa 2. Podemos observar, nesta táboa 2, como as 6 primeiras medidas son relevantes en canto ao nivel das súas reducións e facilidade de implantación destacando dúas entre elas: o balance de nitróxeno e a realización dunha combinación de medidas baixas en carbono dentro da granxa e dos sistemas empregados, mediante a realización dun plan de acción.

9 European Parliament (2014). Measures at farm level to reduce greenhouse gas emissions from EU agriculture. Directorate general for internal policies. Policy department structural and cohesion policies. Agriculture and environmental development. European Parliament.

10 AgriClimateChange (2014). Unha agricultura respectuosa co clima Avaliacións enerxéticas e de emisións de gases de efecto invernadoiro a escala de explotación na Unión Europea. Proxecto LIFE. AgriClimateChange. 
Táboa 2. Priorización das medidas de mitigación a nivel de explotación agraria de acordo aos custos de instauración e ao grao de dificultade para os agricultores.

\begin{tabular}{|l|c|c|c|c|}
\hline Potencial de redución (MtCO2e/ ano) & \multicolumn{3}{|c|}{ Grao de dificultade para os agricultores } \\
\hline Custos de implantación & Doado & Medio & Alto & Total \\
\hline Neutro/ Negativo & & & & \\
\hline Balance de nitróxeno & 21,5 & & & 21,5 \\
\hline Baixo & & & & \\
\hline Plan de medidas baixas en carbono & 30,0 & & & 30,0 \\
\hline Redución consumo de electricidade & 1,0 & & & 1,0 \\
\hline Redución de consumo de fuel & 3,3 & & & 3,3 \\
\hline Plantación de leguminosas & & 4,1 & & 4,1 \\
\hline Utilización do esterco en cultivos & 1,8 & & & 1,8 \\
\hline Baixo/ Medio & & & & \\
\hline Cubertas vexetais de solos & & 22,8 & & 22,8 \\
\hline Agricultura de conservación & & & 16,0 & 16,0 \\
\hline Medio & & & & \\
\hline Utilización de biomasa para calor & & & & 1,0 \\
\hline Medio/ Alto & & & & \\
\hline Almacenaxe do esterco & & & & \\
\hline Instalación enerxía fotovoltaica & & & & \\
\hline Produción de Biogás & & & & \\
\hline Total & & & & \\
\hline
\end{tabular}

Traducido. Fonte: European Parliament (2014). Measures at farm level to reduce greenhouse gas emissions from EU agriculture.

\section{Gráfico 1. Balance de Nitróxeno.}$$
250
$$

250

200

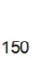

150

100

100

50

$-50$

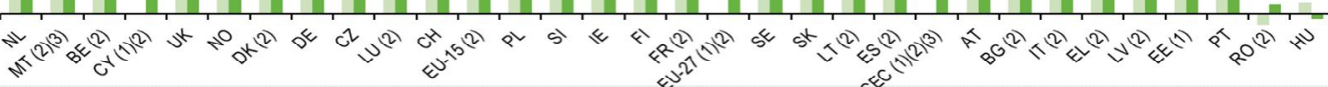

Fonte: Nitrogen surplus (kgN/ ha), average 2001-2004 vs 2005-2008, EU-27(Eurostat) 
A medida de mitigación da realización do balance de nitróxeno consistente en calcular o rendemento real esperado nos cultivos para axustar a aplicación de fertilizantes minerais propúxose debido a que unha conclusión do proxecto é que se aplica un exceso de nitróxeno aos cultivos, que debería estar por debaixo de $50 \mathrm{~kg}$ de N/ ha. e que a meirande parte das explotacións poderían reducir a súa fertilización nitroxenada entre un $5 \%$ e un $15 \%$. Incluso se dan as cantidades de nitróxeno que segundo ese estudo se aporta aos cultivos por enriba das súas necesidades (surplús) nos diferentes países europeos. Estímase unha sobre-aportación media no período 2005 a 2008 de 51 kgN/ ha.

O propio proxecto conclúe que "ademais, o prezo do fertilizante nitroxenado aínda é demasiado baixo en relación cos posibles aforros na compra de menor cantidade de fertilizantes para explotacións de tamaño tan reducido (0,8 ha SAU), polo que non supón un alicerce para os agricultores a súa redución".

Realizar ese balance de nitróxeno por explotación necesitaría asesoramento técnico para aquelas con dificultades de formación, pero algúns países (Noruega, Holanda, Suecia ou Dinamarca) o que fixeron foi por poñer directamente un imposto á utilización de fertilizante nitroxenado, dado que ten unha agricultura moi intensiva e nalgúns casos afectada polo exceso de nitratos en solos.

Porén, supoñer que os agricultores non posúen os coñecementos técnicos axeitados e que aportan máis nitróxeno do necesario é unha conclusión discutible.

Ao tratar de contrastar os resultados de redución de GEI das políticas de mitigación propostas no devandito proxecto, atopamos con que, a ferramenta ACCT, anteriormente mencionada e utilizada para o proxecto, combina as emisións de GEI, os cambios nos stocks de carbono e medidas enerxéticas e os seus cálculos están baesados na pegada de carbono e non nas metodoloxías contables (Directrices) dos inventarios de GEI. O propio modelo ACCT especifica que a análise das emisións de GEI a escala de explotación fanse co formato ISO 14064 e GHG Protocol que son metodoloxías que difiren das regras do inventario de GEI.

Tamén o centro de investigación da Unión Europea (JRC) desenvolveu unha Calculadora de Carbono para analizar todas as emisións a nivel de granxa pero, ademais, múltiple software foi desenvolvido co mesmo propósito e, así, o Grupo de traballo do Congreso Nacional de Medio Ambiente en $2014^{11}$ aporta fichas de nada menos 14 propostas informáticas con este obxectivo.

Aínda que todas estas ferramentas de medición de emisións de GEI sexan útiles para realizar a análise das posibilidades de mitigación a nivel de granxa, os resultados das reducións de GEI no seu conxunto, como medida de mitigación para todo o sector agrario, son moi incertos, xa que non se teñen en conta as ecuacións que se utilizan na elaboración do inventario. Este é un problema fundamental pois se non somos capaces de utilizar a metodoloxía do inventario, non poderemos propoñer medidas de mitigación ou que non sexan as que correspondan ao sector agricultura e por tanto computen noutros sectores, fundamentalmente o enerxético, ou que sexan irreais, que non poidan ser contabilizadas como reducións de forma oficial e, polo tanto, non poderán ser utilizadas para cumprir cos compromisos de redución do país.

Algo semellente ao que ocorre nas medidas a nivel de explotación agraria pode ocorrer coas medias propostas a nivel xeral. Todos os Estados Membro da UE elaboraron

11 CONAMA (2014). Mitigación e adaptación no sector agrario. Coordina: Fundación Global Nature. Grupo de Traballo 1. CONAMA. 2014. 
propostas de medidas de mitigación para o sector agrario e, por exemplo, a proposta de Francia tamén está reflectida neste documento do Parlamento Europeo.

Esta proposta francesa avala claramente a importancia de que as medidas deben ter en conta na súa cuantificación as metodoloxías do inventario e a súa proposta foi elaborada polo INRA na súa Folla de Ruta de xullo de 2013, propoñendo 10 medidas que se descompuxeron en 26 sub-medidas ${ }^{12}$ (véxase o Gráfico 2).

\section{Gráfico 2: Medidas de mitigación Propostas por Francia}

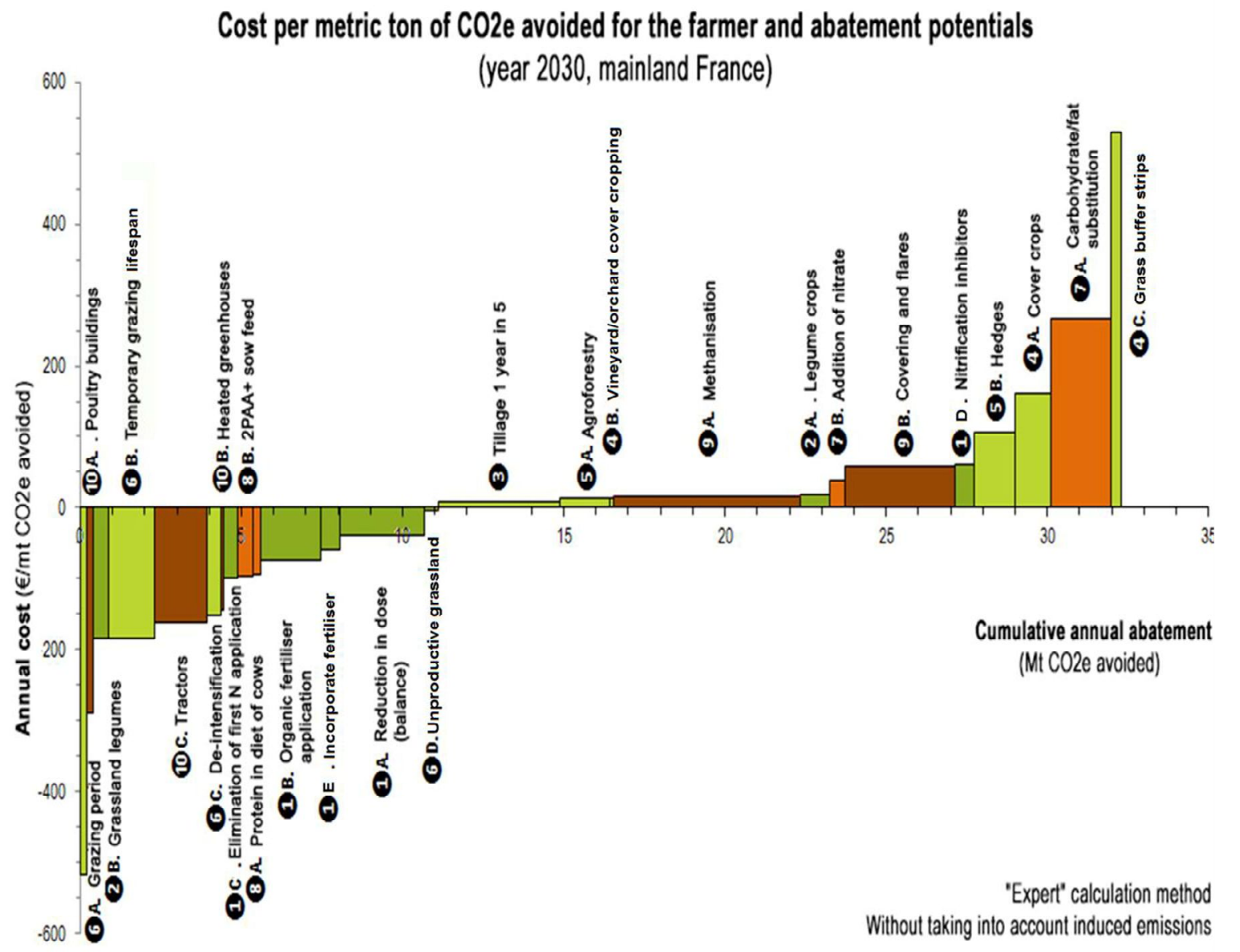

Fonte: European Parliament (2014). Measures at farm level to reduce greenhouse gas emissions from EU agriculture.

Unha das conclusións que especifica a propia proposta francesa é que "realizouse un grande avance na cuantificación das emisións, pero dada a súa natureza difusa e a complexidade dos procesos, a estimación das emisións no sector agrario está afectada por importantes incertezas e a cuantificación dos potenciais de abatemento son bastante menos exactos que os doutros sectores". Expresamente advirten que as ecuacións

12 European Parliament (2014). Measures at farm level to reduce greenhouse gas emissions from EU agriculture. Directorate general for internal policies. Policy department structural and cohesion policies. Agriculture and environmental development. European Parliament. 
empregadas no inventario non son capaces de estimar o potencial de abatemento das medidas de mitigación e en especial as medidas de sumidoiro de carbono. Conclúen na devandita proposta que "se aplicáramos nos cálculos as metodoloxías do inventario, o potencial de abatemento da nosa proposta reduciríase un terzo". Podemos concluír que existen moitas propostas de redución de emisións tanto a nivel de explotación agraria como de país, que se dispón de diferente software para medilas, pero as metodoloxías empregadas difiren das Directrices contables que regulan a elaboración do inventario de GEI dun país.

\subsection{A Folla de Ruta de España}

Profundaremos na descrición desta problemática analizando as medidas de mitigación propostas por España para o sector agrario. Unha das obrigas aprobadas pola Unión Europea ${ }^{13}$ é a de reducir as emisións por parte dos seus Estados Membro mediante a repartición do esforzo entre eles, de acordo á súa situación socioeconómica. Para España correspondeulle realizar o esforzo de reducir as súas emisións de GEI nun 10\% con respecto ás emisións que tiña no ano 2005 para o período 2013-2020. Nunha primeira avaliación, a MAGRAMA considerou que ese compromiso implicaría a baixada de 54 millóns de t. de $\mathrm{CO}_{2 \text {-eq }}$ sobre o obxectivo asignado. Para cumprir coa Decisión europea España elaborou unha Folla de Ruta ${ }^{14}$ na que se propoñen medidas adicionais que deben permitir a España o seu crecemento económico e asemade reducir emisións. A Folla de Ruta examina que medidas son máis axeitadas para abordar esas reducións adicionais, seleccionando aquelas medidas que son custo-eficientes e aquelas medidas que xeren máis actividade económica e emprego. Descríbense, no devandito documento, 43 medidas divididas en seis grandes sectores e entre eles está o chamado sector agricultura. Para cada unha das medidas, preséntase unha descrición dos seus custos e impactos en mitigación, eficiencia, actividade económica e emprego, indicando sobre que universo ou área se aplica. Folla de Ruta: "As medidas que se expoñen a continuación elaboráronse para reducir as emisións dentro do sector agrícola e gandeiro naquelas actividades que supoñen maiores emisións de acordo ás categorías do inventario nacional de emisións de gases de efecto invernadoiro, como son os solos agrícolas, a xestión de estercos e a utilización de combustibles fósiles por parte da maquinaria agrícola". As medidas propostas no "sector agrícola e gandeiro" expóñense na Táboa 3. Á Hoja de Ruta acompáñalle un segundo documento de ANEXOS no que se especifica como se calcularon as reducións de emisións que se conseguirían coa aplicación destas medidas. A elaboración da Folla de Ruta por España supón un paso moi importante de formulación de políticas de mitigación, pois, non só analiza ás meras formulacións de reducir emisións de GEI, senón que as introduce no contexto socioeconómico no que deben ser instituídas. Analiza a súa eficiencia con relación ao custo e o seu impacto no emprego e utiliza a modelización para que ao final poidamos tomar unha decisión sobre aquelas medidas que deberían ser instituídas baseándose nunha información moito máis holística que a mera redución de emisións.

Estimando o grande esforzo e calidade do traballo realizado para elaborar estas medidas de mitigación, realízanse, a continuación, unha serie de observacións para resaltar a

13 Parlamento Europeo e Consello da Unión Europea (2009). Decisión 406/2009/ CE do Parlamento Europeo e do Consello do 23 de abril de 2009 sobre o esforzo dos Estados membro para reducir as súas emisións de gases de efecto invernadoiro a fin de cumprir cos compromisos adquiridos pola Comunidade ata 2020.

14 Oficina Española de Cambio Climático (2014). Folla de ruta dos sectores difusos a 2020. MAGRAMA. Oficina Española de Cambio Climático. 
importancia da necesaria coordinación co inventario español de GEI e destacar a dificultade e complexidade de deseñar medidas para o sector agricultura.

\section{Táboa 3. Medidas de mitigación para o sector agrícola e gandeiro}

\begin{tabular}{|c|c|c|c|}
\hline ? & $\begin{array}{l}\text { Dixestión anaeróbica de xurros co } \\
\text { tratamento de nitrificación } \\
\text { desnitrificación }\end{array}$ & ? & $\begin{array}{lcc}\text { Introdución de cubertas } & \text { de } \\
\text { leguminosas } & \text { sementadas } & \text { en } \\
\text { cultivos leñosos en regadío. } & \end{array}$ \\
\hline ? & $\begin{array}{l}\text { Dixestión anaeróbica de } \\
\text { dexeccións gandeiras e outros } \\
\text { cosubstratos }\end{array}$ & ? & $\begin{array}{l}\text { Incorporación ao solo dos } \\
\text { residuos de poda de cultivos } \\
\text { leñosos }\end{array}$ \\
\hline ? & $\begin{array}{l}\text { Introdución de leguminosas nas } \\
\text { pradeiras xestionadas que } \\
\text { utilizaran fertilización sintética }\end{array}$ & ? & $\begin{array}{l}\text { Utilización dos residuos da poda } \\
\text { de cultivos leñosos evitando a súa } \\
\text { queima }\end{array}$ \\
\hline ? & Sementeira directa & 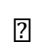 & Condución eficiente de tractores \\
\hline ? & $\begin{array}{l}\text { Formación para mellorar a } \\
\text { eficiencia na fertilización }\end{array}$ & & \\
\hline
\end{tabular}

Fonte: Oficina Española de Cambio Climático (2014). Folla de ruta dos sectores difusos a 2020. MAGRAMA. Oficina Española de Cambio Climático.

En España, segundo o inventario nacional de GEI15, no ano 2012 as actividades con maiores emisións foron os Solos Agrícolas, que produxeron o 48,3\% das emisións do sector, seguidas pola Fermentación Entérica el 27,7\% e a Xestión de Estercos o 21,8\%. Á vista das medidas propostas (Táboa 3) e a clasificación de categorías do inventario, podemos afirmar que non se cumpre de todo o criterio de que se elaborasen de acordo ás categorías do inventario nacional, pois non se inclúe ningunha medida de redución para as emisións debidas á fermentación entérica, o 27,7\% das emisións do sector. Algunhas observacións pódense formular sobre a devandita Folla de Ruta, como, por exemplo, que as fichas que acompañan a cada medida non informan abondo do xeito no que se calculan as reducións e é complicado saber a relación co inventario e, asemade, é difícil deducir se utilizan as Directrices de 1996 ou as Directrices de 2006 á hora de realizar os cálculos do potencial de abatemento, por exemplo, no tratamento da fixación biológica de nitróxeno. Propóñense medidas (véxase a Táboa 3) que tratan de reducir o consumo de combustibles fósiles, como, por exemplo, a condución eficiente de tractores, a sementeira directa (non se ten en conta a evitación de emisións do na laboría do solo. Non entraría na directiva de esforzo xa que pertence ao apartado UTCUTS), que versan sobre a redución de combustible e contabilizarían no apartado enerxético. A utilización dos residuos de poda de cultivos leñosos evitando a súa queima que se destinan a biomasa para substituír combustible fósiles contabilizaría tamén no sector enerxético. As reducións acadadas con estas tres medidas computarían, a efectos de inventario, e por tanto das medidas de esforzo, no sector enerxético e poñelas neste sector pode inducir a confusión. Só seis medidas pertencerían estritamente ao sector agricultura como está definido no inventario de GEI. E dicir, "a clasificación contable" non sería correcta. Por exemplo, a medida de "Introdución de leguminosas en pradeiras xestionadas que utilizaran fertilización sintética" e utilizando os datos obxectivos que aporta, podería dicirse que ten escasa 
relevancia e efectividade, ademais de suscitar dúbidas teóricas, e quizabes debería propiciar a súa reformulación. Vemos que o obxectivo desta medida é reducir as emisións dos solos de pradeiras de regadío mediante a incorporación de leguminosas na pradeira, de tal xeito que a fixación de nitróxeno atmosférico, que producen as leguminosas compensa a necesidade de utilizar fertilizantes minerales. $O$ universo ao que aplica esta medida é o terreo dedicado en España a cultivo de pradeiras polifitas en regadío.

Táboa 4. Cálculo do carbono total liberado na queima en campo aberto.

\begin{tabular}{|c|c|c|c|c|c|c|c|c|c|c|c|c|c|}
\hline Año & Cultivo & $\begin{array}{c}\text { Producción } \\
\text { Total }(t)\end{array}$ & $\begin{array}{c}\text { Tasa } \\
\text { residuo } \\
\text { cultivo }\end{array}$ & $\begin{array}{l}\text { Cantidad } \\
\text { de } \\
\text { residuos } \\
\text { (t) }\end{array}$ & $\begin{array}{l}\text { Fracción } \\
\text { de } \\
\text { Materia } \\
\text { seca }\end{array}$ & $\begin{array}{c}\text { Cantidad } \\
\text { de } \\
\text { materia } \\
\text { seca } \\
\text { residuos } \\
\text { (t) }\end{array}$ & $\begin{array}{c}\text { Porcentaje } \\
\text { quemado } \\
\%\end{array}$ & $\begin{array}{c}\text { Fracción } \\
\text { de } \\
\text { Biomasa } \\
\text { Oxidada }\end{array}$ & $\begin{array}{c}\text { Biomasa } \\
\text { total } \\
\text { quemada } \\
\text { (t) }\end{array}$ & $\begin{array}{c}\text { Fracción } \\
\text { de } \\
\text { carbono }\end{array}$ & $\begin{array}{l}\text { Fracción } \\
\text { de } \\
\text { nitrógeno }\end{array}$ & $\begin{array}{l}\text { C total } \\
\text { liberado } \\
\text { (t) }\end{array}$ & $\begin{array}{c}\mathrm{N} \text { total } \\
\text { liberado } \\
\text { (t) }\end{array}$ \\
\hline & & A & $B$ & $C=A \times B$ & D & $\mathrm{E}=\mathrm{C} \times \mathrm{D}$ & $\mathrm{F}$ & $\mathrm{G}$ & $\mathrm{H}=\mathrm{E} \times \mathrm{F} \times \mathrm{G}$ & 1 & $\mathrm{~J}$ & $\mathrm{~K}=\mathrm{H} \times \mathrm{I}$ & $\mathrm{L}=\mathrm{H} \times \mathrm{l}$ \\
\hline 1990 , & AnтоZ & 569.960 & 1,4 & 797.944 & 0,85 & 678.253 & 7,14 & 0,9 & 43.602 & 0,4144 & 0,0067 & 718.069 & 292 \\
\hline 1990 & Avena & 511.588 & 1,3 & 665.064 & 0,92 & 611.859 & 7,14 & 0,9 & 39.334 & 0,4118 & 0,007 & $7 \mid 16.198$ & 275 \\
\hline 1990 & Cebada & 9.382 .114 & 1,2 & 11.258 .537 & 0,85 & 9.569 .756 & 7,14 & 0,9 & 615.199 & 0,4567 & 0,0043 & 3280.961 & 2.645 \\
\hline 1990 & Centeno & 267.318 & 1,6 & 427.709 & 0,9 & 384.938 & 7,14 & 0,9 & 24.746 & 0,384 & 0,0048 & $\begin{array}{l}9.502 \\
\end{array}$ & 119 \\
\hline 1990 & $\begin{array}{l}\text { Col y } \\
\text { repollo }\end{array}$ & 424.451 & 4 & 1.697 .804 & 0,14 & 237.693 & 50,00 & 0,9 & 106.962 & 0,41 & 0,0274 & 4 43.854 & 2.931 \\
\hline 1990 & Espinaca & 54.573 & 0,25 & 13.643 & 0,09 & 1.228 & 50,00 & 0,9 & 553 & 0,41 & 0,0274 & 227 & 15 \\
\hline 1990 & \begin{tabular}{|l|}
$\begin{array}{l}\text { Guisante } \\
\text { verde }\end{array}$ \\
\end{tabular} & 67.369 & 1,5 & 101.053 & 0,87 & 87.916 & 50,00 & 0,9 & 39.562 & 0,2415 & 0,0142 & 9.554 & 562 \\
\hline 1990 & $\begin{array}{l}\text { Judia } \\
\text { verde }\end{array}$ & 276.477 & 2,1 & 580.602 & 0,86 & 499.318 & 50,00 & 0,9 & 224.693 & 0,2041 & 0,012 & $2 \quad 45.860$ & 2.696 \\
\hline 1990 & Lechuga & 984.990 & 0,18 & 177.298 & 0,05 & 8.865 & 50,00 & 0,9 & 3.989 & 0,44 & 0,0314 & 1.755 & 12 \\
\hline 1990 & Maíz & 3.041 .895 & 1 & 3.041 .895 & 0,78 & 2.372 .678 & 7,14 & 0,9 & 152.529 & 0,4709 & 0,0081 & 71.826 & .23 \\
\hline 1990 & \begin{tabular}{|l|} 
Olivar \\
aderezo
\end{tabular} & 213.350 & 1,13 & 241.086 & 0,7815 & 188.409 & 78,00 & 0,9 & 132.263 & 0,4952 & 0,0039 & 65.497 & 5 \\
\hline 1990 & \begin{tabular}{|l} 
Olivar \\
almazara
\end{tabular} & 3.137 .708 & 1,13 & 3.545 .611 & 0,7815 & 2.770 .895 & 78,00 & 0,9 & 1.945 .168 & 0,4952 & 0,0039 & 963.247 & 7.586 \\
\hline 1990 & Patata & 5.330 .733 & 0,43 & 2.292 .215 & 0,45 & 1.031 .497 & 100,00 & 09 & 928.347 & 0,4226 & 0,011 & 392.320 & 10.212 \\
\hline 1990 & Soja & 42.184 & 2,1 & 88.586 & 0,87 & 77.070 & 50,00 & 0,9 & 34.681 & 0,3912 & 0,023 & 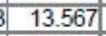 & 79 \\
\hline 1990 & Sorgo & 88.866 & 1,4 & 124.413 & 0,91 & 113.216 & 7,14 & 0,9 & 7.278 & 0,54 & 0,0108 & 3.930 & TE \\
\hline 1990 & Trigo & 4.773 .550 & 1,3 & 6.205 .614 & 0,85 & 5.274 .772 & 7,14 & 0,9 & 339.092 & 0,4853 & 0,0028 & 164.562 & 2 \\
\hline 1990 & $\begin{array}{l}\text { Viñedo } \\
\text { mesa }\end{array}$ & 476.790 & 0,43 & 205.020 & 0,736 & 150.894 & 78,00 & 0,9 & 105.928 & 0,57 & 0,0036 & 5 60.379 & 381 \\
\hline 1990 & $\begin{array}{l}\text { Viñedo } \\
\text { vino }\end{array}$ & 6.212 .835 & 0,43 & 2.671 .519 & 0,736 & 1.966 .238 & 78,00 & 0,9 & 1.380 .299 & 0,57 & 0,0036 & 786.770 & 4.969 \\
\hline
\end{tabular}

Fonte: MAGRAMA (2014b). España, Informe Inventarios GEI 1990-2012 (Abril de 2014). MAGRAMA

O cálculo é un hipotético aforro de fertilizante mineral, pero se a pradeira xa é polifita, á hora de facer os cálculos, como discriminamos que esa pradeira non ten xa incorporada unha leguminosa?, como podemos saber que esa pradeira polifita está só formada por gramíneas? As estatísticas dinos que en España en 2012 houbo 42.793 has. de pradeiras polifitas en regadío e a ficha do Anexo cos cálculos indícanos que se podería actuar sobre un 10\% desa superficie (4.279 has.) do ano 2008 ao ano 2020. Indica que as reducións

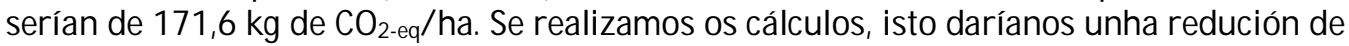

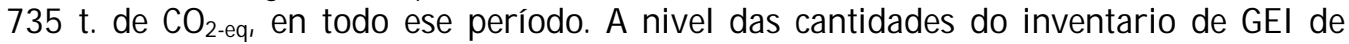
España (37 millóns de t. de $\mathrm{CO}_{2 \text {-eq }}$ no sector agricultura en 2012) parece un pouco irrelevante reducir esa cantidade de 735 t. de $\mathrm{CO}_{2 \text {-eq }}(0,02 \%)$ en todo o período 20132020. É probable que estas cuestións se vaian corrixindo en sucesivas versións, pero sinxelamente trátase de reflectir, mediante un exemplo, a dificultade de deseñar unha medida que sexa efectiva a nivel de inventario. Outra das medidas propostas é a incorporación ao solo dos residuos de poda de cultivos leñosos na que nos indica que evita as emisións de $\mathrm{CH}_{4}$ e $\mathrm{N}_{2} \mathrm{O}$ xeradas pola queima dos residuos de poda xerados nunha hectárea en produción de oliveira, viñedo, froiteiros e froitos secos. O universo que se considerou é toda a superficie en produción en España dedicada a oliveira, viñedo, froiteiros e froitos secos. É moi importante saber como trata este tema da queima de residuos o inventario español de GEI. Os datos de actividade no inventario obtéñense dunha táboa na que publica unha serie de parámetros como, a taxa de residuo que deixa 0 
cultivo e as súas fraccións de contido de materia seca, carbono e nitróxeno. Dado que non posúe datos de boa calidade de todos os cultivos, indícanos que só incorpora ao inventario os cultivos con datos de boa calidade, que coinciden, para os cultivos leñosos, fundamentalmente coa oliveira e o viñedo. Non entran nin os froiteiros nin os froitos secos. Utilizando a Análise por Actividades SNAP 16 da que se nutre o Inventario de GEI podemos observar, na Táboa 4, como soamente se utilizan os datos de viñedo e oliveira.

Analizando o inventario español de $\mathrm{GEI}^{17}$, podemos apreciar que as emisións xeradas no ano 2012 pola queima de residuos xeraron nese ano unhas emisións para España de 518,47 Gg. de $\mathrm{CO}_{2 \text {-eq }}$ (véxase a Táboa 5).

\section{Táboa 5}

\begin{tabular}{|c|c|c|c|c|c|c|c|c|c|}
\hline 4. Agricultura & $37.658,52$ & $36.311,19$ & $43.465,63$ & $40.040,77$ & $38.013,21$ & $38.067,93$ & $39.305,25$ & $37.915,43$ & $37.714,79$ \\
\hline A. Fermentación entérica & $11.120,26$ & $10.950,92$ & $11.930,61$ & $11.757,43$ & $11.245,78$ & $11.161,45$ & $10.943,33$ & $10.513,31$ & $10.259,82$ \\
\hline B. Gestión del estiércol & $6.517,08$ & $7.097,55$ & $8.108,57$ & $8.493,60$ & $8.436,23$ & $8.364,05$ & $8.199,49$ & $8.264,46$ & $8.462,25$ \\
\hline C. Cultivo de arroz & 227,45 & 137,22 & 294,90 & 300,26 & 240,53 & 300,39 & 307,90 & 307,59 & 307,59 \\
\hline D. Suelos agricolas & $19.255,69$ & $17.614,73$ & $22.657,46$ & $19.159,72$ & $17.689,26$ & $17.772,55$ & $19.362,03$ & $18.311,60$ & $18.166,66$ \\
\hline \multicolumn{10}{|l|}{ E. Quemas planificadas de sabanas } \\
\hline $\begin{array}{l}\text { F. Quema en campo de residuos } \\
\text { agricolas }\end{array}$ & 538,03 & 510,76 & 474,09 & 329,76 & 401,41 & 469,49 & 492,49 & 518,47 & 518,47 \\
\hline G. Otros & & & & & & & & & \\
\hline
\end{tabular}

Fonte: MAGRAMA (2014b). España, Informe Inventarios GEI 1990-2012 (Abril de 2014). MAGRAMA

Pero como vimos na táboa 4 só computan as podas de oliveira e viñedo (e non figuran os froiteiros e froitos secos) e o propio inventario recolle que "a queima de residuos se fundamenta principalmente nas emisións da poda da oliveira e do viñedo e as súas flutuacións son provocadas polos cambios interanuais nas súas respectivas producións". Porén, a medida proposta inclúe, no universo da medida, as emisións debidas á queima das podas de froiteiros e froitos secos, de 1.300.000 has, ${ }^{18}$ adicadas a estes cultivos, pero no devandito inventario estas emisións non se están contabilizando. Polo tanto, estase propoñendo a redución dunha emisión, que tecnicamente é correcta, pero que da análise realizada no inventario español non parece deducirse que se estea contabilizando. Se algo non se computa como emisión, non se pode dicir que se reduce pois oficialmente non existe.

En conclusión, cando se deseñe unha medida que propón reducir as emisións é moi importante primeiro estar seguros de que se contabilizou previamente. Daí que sexa tan necesario coñecer en profundidade o inventario de GEI e as súas regras contables para evitar contradicións e que as medidas deseñadas sexan efectivas na súa capacidade redutora.

\section{Análise da FAO}

Veremos a continuación que non soamente o coñecemento fondo das Directrices de elaboración do inventario de GEI nos será suficiente para propoñer medidas de mitigación, senón que se atopan á súa vez influídas por outras circunstancias e para o seu estudo utilízase unha análise da FAO.

\footnotetext{
16 MAGRAMA (2014c). Inventarios Nacionais de Emisións á Atmósfera 1990-2012. Volume 2: Análise por Actividades SNAP. MAGRAMA.

17 MAGRAMA (2014b). España, Informe Inventarios GEI 1990-2012 (Abril de 2014). MAGRAMA.

18 MAGRAMA (2014a). Enquisa sobre Superficies e Redementos de Cultivos en España, ano 2013 (ESYRCE). MAGRAMA.
} 
A FAO como organismo da ONU adicado á agricultura e á alimentación fundamentalmente para os países en vías de desenvolvemento tamén realizou as súas propostas de medidas de mitigación das emisións de GEI debidas á actividade agraria.

Un dos documentos elaborado pola $\mathrm{FAO}^{19}$ que analiza todas estas cuestións presenta unha revisión das diversas opcións técnicas para a redución das emisións, na gandeiría, de gases diferentes ao $\mathrm{CO}_{2}$. O documento proporciona moitas medidas prácticas de redución dende a diminución do $\mathrm{CH}_{4}$ entérico (Aditivos alimenticios e estratexias de alimentación), as estratexias de xestión do esterco, que ofrecen oportunidades de mitigación ou as estratexias de manexo dos animais, etc. coas potencialidades redutoras de cada medida.

Sen entrar a analizar as diferentes medidas propostas, o que se pretende neste traballo, é destacar unhas reflexións interesantes que o devandito documento aporta. Así, indícanos que moitas das propostas de medidas de mitigación se realizan de forma illada e rara vez discútense as posibles interaccións no contexto de todo o sistema de produción. Os deseñadores das medidas de mitigación deberían ser conscientes de que se poden propoñer prácticas de mitigación que dunha banda reduzan emisións e doutra as incrementen. $\mathrm{O}$ resultado final pode ser que non produzamos ningunha redución ou ata que incrementemos as emisións.

Neste estudo da FAO citan unha investigación realizada a partir dunha simulación das explotacións leiteras do Reino Unido, (Prado et al. 2010): “a eficacia dunha combinación de prácticas de mitigación dos GEI non se pode avaliar mediante a simple adición da eficacia de cada método aplicado por separado". Estes autores calcularon unha redución do $45 \%$ das emisións dos GEI (por litro de leite producido) cando se aplicaron simultaneamente de 5 a 8 prácticas de mitigación, en comparación cunha redución do 55$65 \%$ cando sinxelamente se engadiron os potenciais de mitigación de cada práctica aplicada individualmente.

Así mesmo, é importante que as avaliacións das prácticas de mitigación teñan en conta a "contaminación de intercambio", é dicir, a diminución da emisión dun GEI namentres se aumenta a do outro, ou o aumento da emisión do mesmo gas "augas enriba ou augas abaixo". A contaminación de intercambio pode ocorrer, por exemplo, como resultado da manipulación da dieta. Así, a redución do $\mathrm{N}$ dietético para mitigar as emisións de $\mathrm{N}_{2} \mathrm{O}$ proveniente da aplicación do esterco ao solo pode aumentar a emisión entérica de $\mathrm{CH}_{4}$ debido ao aumento da inxestión de carbohidratos (asumindo que os carbohidratos substitúen proteína na dieta). Ademais a diminución do $\mathrm{CH}_{4}$ entérico debida á inclusión de cereais na dieta pode ser parcialmente contrarrestada por un aumento nas emisións de $\mathrm{CH}_{4}$ do esterco. As interaccións entre os compoñentes individuais dos sistemas de produción agropecuaria son moi complexas e deben ser consideradas cando se recomendan prácticas de mitigación dos GEI. Unha práctica podería mitigar exitosamente as emisións de $\mathrm{CH}_{4}$ entérico, pero aumentar o substrato fermentable, que aumentaría as emisións de $\mathrm{CH}_{4}$ do esterco almacenado ou a dispoñibilidade de $\mathrm{N}$ para aumentar as emisións de $\mathrm{N}_{2} \mathrm{O}$ provenientes dos solo fertilizado con esterco. Pola contra, algunhas das prácticas de mitigación son sinérxicas e se espera que diminúan tanto as emisións dos GEI entéricos como as do esterco (por exemplo, mellorar a sanidade e a produtividade animal). Podemos concluír que as medidas de mitigación que apliquemos a un subsector poden interactuar e/ ou ser contraditorias ou ser sinérxicas entre elas.

19 Pierre J. Gerber et al. (2013). Mitigación das emisións de gases de efecto invernadoiro na produción gandeira. Unha revisión das opcións técnicas para a redución das emisións de gases diferentes ao $\mathrm{CO}_{2}$. FAO,2013 


\subsection{O subsector leitero europeo}

Dado que como vimos o estudo da FAO menciona como unha boa medida de mitigación, de carácter sinérxico, o aumento da produtividade, a continuación, contrástase esta afirmación, mediante a análise das emisións de metano debidas á fermentación entérica do subsector bovino leitero da Unión Europea. Utilizando o Inventario de GEI da Unión Europea que é realizado pola Axencia Europea de Medio Ambiente ${ }^{20}$ podemos observar que, dentro das emisións do sector agrario europeo, un dos epígrafes que máis emisións produce é a fermentación entérica do gando vacuno que produce un $27 \%$ das emisións. Na fermentación entérica considéranse as emisións de metano e a cantidade producida e emitida deste gas, polos animais, que depende basicamente da constitución do seu aparello dixestivo e da súa dieta alimentaria. As vacas leiteras, como ruminantes que son, producen unha gran cantidade de metano e en canto á dieta, pódese dicir que canto maior sea a inxesta e menor a dixestibilidade das materias que compoñen a dieta, maiores serán, en termos xerais, as emisións de metano. Pola súa banda, a inxesta animal relaciónase positivamente co tamaño do animal, a súa taxa de crecemento e, neste caso, coa súa produción de leite. Para calcular as emisións debidas á fermentación entérica, un dos factores que se debe calcular é a enerxía bruta que inxere o animal a través da alimentación que lle damos e que é necesaria para realizar as súas funcións vitais tanto de mantemento, crecemento, xestación, actividade e produción de leite. Podemos observar na seguinte Táboa 7, referido aos países da Unión Europea 15, as cantidades de enerxía que se subministra na dieta a cada vaca leitera (Mj/ cabeza/ día), a dixestibilidade que ten, o peso medio de cada vaca e os litros de leite que produce por cabeza e día.

Táboa 7. Enerxía consumida, peso, produción de leite por vaca leitera e día e dixestibilidade do alimento. Anos 2012 e 1990.

\begin{tabular}{|l|r|r|r|r|}
\hline Member State & \multicolumn{4}{|c|}{ Dairy Cattle } \\
\cline { 2 - 5 } \multicolumn{1}{|c|}{$\mathbf{2 0 1 2}$} & $\begin{array}{r}\text { Feed } \\
\text { Intake }\end{array}$ & $\begin{array}{r}\text { Animal } \\
\text { Weight } \\
(\mathrm{kg})\end{array}$ & $\begin{array}{r}\text { Mlk } \\
\text { prod. }{ }^{1)}\end{array}$ & $\begin{array}{r}\text { Feed } \\
\text { Digest. } \\
(\%)\end{array}$ \\
\hline Austria & 302 & 700 & 18 & 71 \\
\hline Belgium & 336 & 600 & 21 & 75 \\
\hline Denmark & 344 & 580 & 23 & 71 \\
\hline Finland & 331 & 649 & 22 & 70 \\
\hline France & 297 & $\mathrm{NA}$ & 19 & $\mathrm{NA}$ \\
\hline Germany & 321 & 646 & 20 & 75 \\
\hline Greece & 275 & 600 & 16 & 65 \\
\hline Ireland & 245 & 535 & 14 & 75 \\
\hline Italy & 295 & 603 & 18 & 65 \\
\hline Luxembourg & 306 & 650 & 20 & 70 \\
\hline Netherlands & 335 & $\mathrm{NA}$ & $\mathrm{NA}$ & $\mathrm{NA}$ \\
\hline Portugal & 308 & 600 & 22 & 73 \\
\hline Spain & 310 & 647 & 21 & 70 \\
\hline Sw eden & 321 & $\mathrm{NA}$ & 24 & 69 \\
\hline United Kingdom & 281 & 637 & 20 & 75 \\
\hline EU-15 & 305 & 624 & 19 & 72 \\
\hline
\end{tabular}

\begin{tabular}{|l|r|r|r|r|}
\hline Member State & \multicolumn{4}{|c|}{ Dairy Cattle } \\
\cline { 2 - 5 } \multicolumn{1}{|c|}{1990} & $\begin{array}{r}\text { Feed } \\
\text { Intake }{ }^{1)}\end{array}$ & $\begin{array}{r}\text { Animal } \\
\text { Weight } \\
(\mathrm{kg})\end{array}$ & $\begin{array}{r}\text { Mlk } \\
\text { prod. }{ }^{11}\end{array}$ & $\begin{array}{r}\text { Feed } \\
\text { Digest. } \\
(\%)\end{array}$ \\
\hline Austria & 247 & 700 & 10 & 66 \\
\hline Belgium & 261 & 600 & 11 & 75 \\
\hline Denmark & 278 & 550 & 17 & 71 \\
\hline Finland & 253 & 520 & 16 & 70 \\
\hline France & 242 & $\mathrm{NA}$ & 13 & $\mathrm{NA}$ \\
\hline Germany & 260 & 608 & 13 & 73 \\
\hline Greece & 199 & 600 & 7 & 65 \\
\hline Ireland & 222 & 535 & 11 & 75 \\
\hline Italy & 240 & 603 & 12 & 65 \\
\hline Luxembourg & 247 & 650 & 13 & 70 \\
\hline Netherlands & 280 & $\mathrm{NA}$ & $\mathrm{NA}$ & $\mathrm{NA}$ \\
\hline Portugal & 227 & 600 & 12 & 73 \\
\hline Spain & 225 & 598 & 10 & 69 \\
\hline Sw eden & 276 & $\mathrm{NA}$ & 19 & 69 \\
\hline United Kingdom & 222 & 572 & 14 & 75 \\
\hline EU-15 & 247 & 595 & 13 & 71 \\
\hline
\end{tabular}

Fonte ${ }^{21}$

Como podemos observar no Gráfico 4 a mellora do rendemento leitero por cabeza no período 1990-2012 foi xeneralizada nos países europeos subindo un 51\% de media e, como é lóxico, foi acompañada dunha subida do consumo de enerxía por cabeza (Gráfico

20 EEA, European Environment Agency (2014). Annual European Union greenhouse gas inventory 1990-2012 and inventory report 2014. European Environment Agency.

21 EEA, European Environment Agency (2014). Annual European Union greenhouse gas inventory 1990-2012 and inventory report 2014. European Environment Agency. 
3) pero non tan importante proporcionalmente, soamente un 24\%. É dicir, cun incremento menor da inxesta de enerxía, obtívose un maior incremento do rendemento leitero.

Pero tamén podemos observar no Gráfico 5 como descendeu o número de vacas en Europa unha media do 33\% e, porén, a produción de leite mantívose practicamente estable no período (véxase a Táboa 8).

Os gráficos 3 e 4 amosan a evolución entre 1990 e 2012 da enerxía subministrada a cada animal e a súa produción leitera.

Gráfico3

Evolución do consumo de enerxía por vaca leitera e día de 1990 a 2102

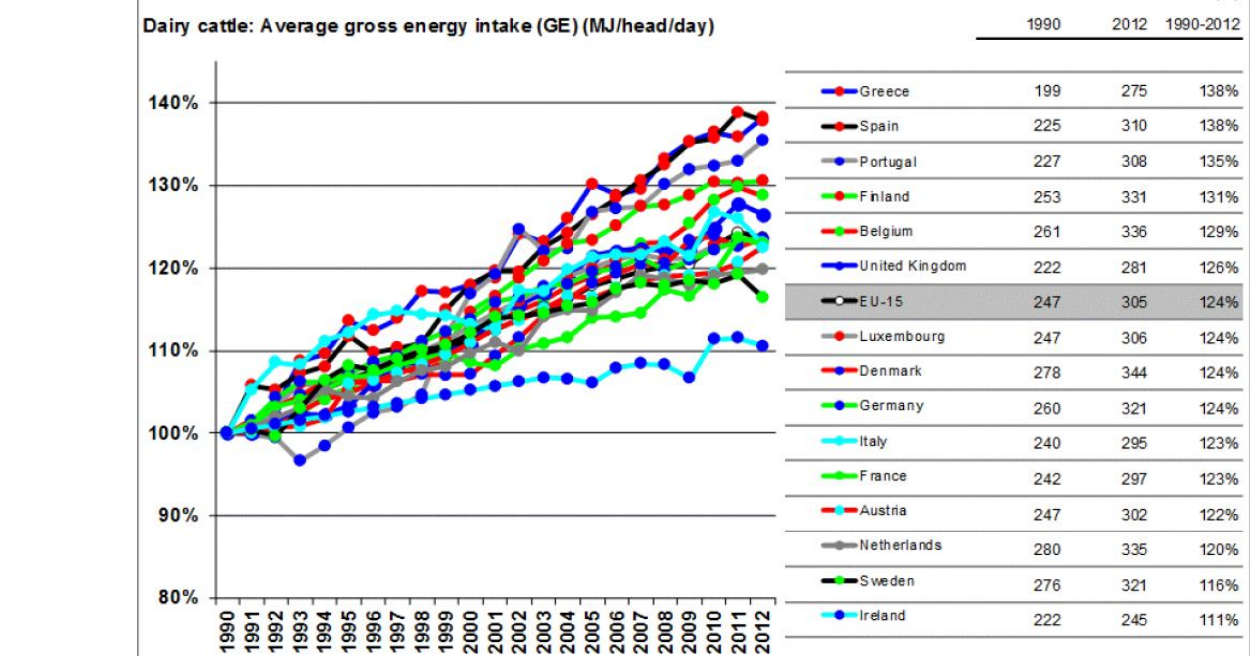

Fonte22

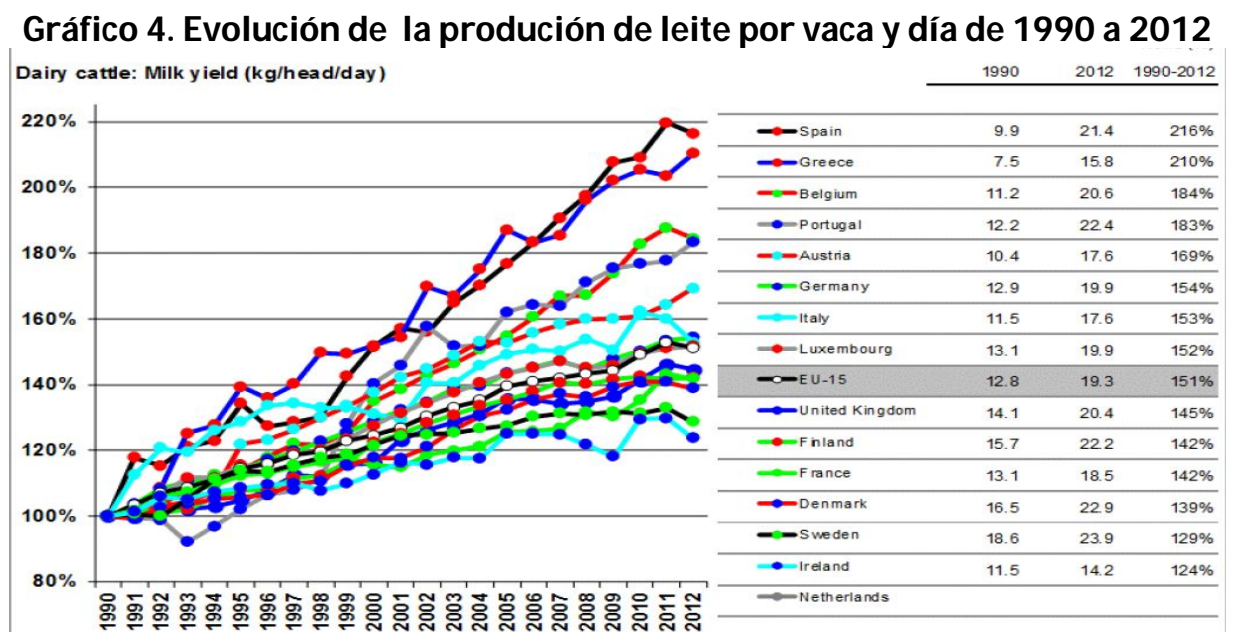

Fonte 23

22 EEA, European Environment Agency (2014). Annual European Union greenhouse gas inventory 1990-2012 and inventory report 2014. European Environment Agency.

23 EEA, European Environment Agency (2014). Annual European Union greenhouse gas inventory 1990-2012 and inventory report 2014. European Environment Agency. 
Tabla 8

\begin{tabular}{|l|l|l|}
\hline Unión Europea 15 & 1990 & 2012 \\
\hline Produción de leite en t. & 335.500 & 338.500 \\
\hline Fonte $^{24}$ & &
\end{tabular}

\section{Gráfico 5. Evolución do número de vacas de leite 1990-2012}

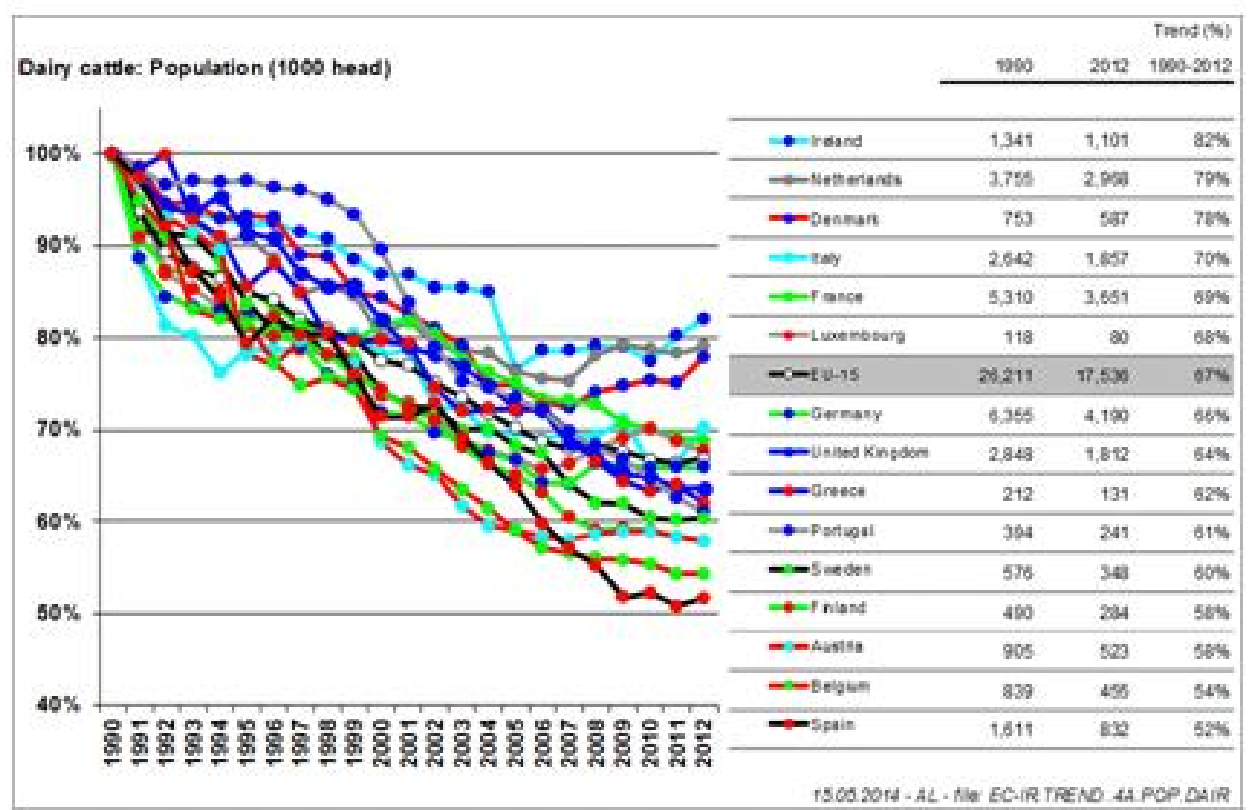

Fonte 25

O resumo destes datos aportanolo o mesmo inventario europeo (véxase a Táboa 9) no que se obtén unha redución de emisións de metano por fermentación entérica do $20 \%$ do ano 1990 ao ano 2012. Indubidablemente o factor de emisión por vaca aumenta un 19\% debido á necesidade de inxerir máis enerxía para producir máis leite por cabeza, pero como o número de vacas descende nun 33\%, o resultado final dá unha redución de máis de 600.000 t. de metano.

Podemos concluír que o incremento da produtividade, é dicir, os litros de leite por vaca será unha boa medida de mitigación de emisións. Ese incremento da produtividade que nos permite producir o mesmo leite con menos número de vacas serve tamén para a redución de emisións do esterco, pois menos vacas producirán menos esterco. O incremento da produtividade (intensificación da produción) por vaca é unha medida sinérxica a efectos do inventario de emisións. O obxectivo ambiental global da medida merecería unha reflexión máis fonda, no obxecto deste traballo, pois, por exemplo, sería contraria á medida de extensificación das explotacións gandeiras propugnada pola PAC, polo que 0 debate está aberto.

24 EEA, European Environment Agency (2014). Annual European Union greenhouse gas inventory 1990-2012 and inventory report 2014. European Environment Agency.

25 EEA, European Environment Agency (2014). Annual European Union greenhouse gas inventory 1990-2012 and inventory report 2014. European Environment Agency. 
Táboa 9

\begin{tabular}{|l|r}
\hline 1990 & Dairy Cattle \\
\hline & \\
\hline $\mathrm{CH}_{4}$ emissions [Gg CH & \\
\hline Animal population [1000 heads] & 2,697 \\
\hline Implied $\mathrm{F}(\mathrm{kg} \mathrm{CH} / \mathrm{head} / \mathrm{yr})$ & 26,211 \\
\hline
\end{tabular}

\begin{tabular}{|l|r}
\hline 2012 & Dairy Cattle \\
\hline & \\
\hline $\mathrm{CH}_{4}$ emissions $[\mathrm{Gg} \mathrm{CH}$ & \\
\hline Animal population $[1000$ heads] & 2,153 \\
\hline Implied $\mathrm{E}(\mathrm{kg} \mathrm{CH} / \mathrm{head} / \mathrm{yr})$ & 17,536 \\
\hline
\end{tabular}

\begin{tabular}{|l|rr}
\hline & \multicolumn{2}{|c}{ Dairy Cattle } \\
\hline Percent change 1990-2012 & & \\
\hline CH4 emissions [Gg CH4] & $-20 \%$ & $80 \%$ \\
\hline Animal population [1000 heads] & $-33 \%$ & $67 \%$ \\
\hline Implied E (kg CH4/head/yr) & $+19 \%$ & $119 \%$ \\
\hline
\end{tabular}

Fonte 26

\section{Innovacións tecnolóxicas: Nova Zelanda}

Por contraste coas propostas de mitigación da FAO, que elabora as súas propostas principalmente para países en desenvolvemento, neste apartado, trátase de amosar as posibilidades de propoñer medidas de mitigación que incorporen algún tipo de innovación tecnolóxica e que poida ser contabilizada no inventario sen que a súa metodoloxía estea expresamente reflectida nas Directrices.

Por exemplo, Nova Zelanda, que é un país cun importante sector agrario, reflicte claramente a importancia das emisións no seu inventario de GEI27 para a agricultura, pois representan nada menos que o $46 \%$ das súas emisións totais fronte ao $10 \%$ da Unión Europea. É, polo tanto, un dos países máis interesados en reducir as súas emisións debidas a este sector e, ademais, ao ser un país desenvolvido e ter a súa agricultura cun alto grao de tecnificación, pódenos servir de guía para elaborar propostas para o noso sector agrario. No Anexo incluímos unha análise das devanditas innovacións.

\section{Conclusións}

A complexidade e problemática do deseño das medidas de mitigación das emisións da agricultura, que tratamos de plasmar neste traballo, así como o, ás veces, descoñecemento sobre todas estas regras contables, fai que a elaboración de medidas de mitigación específicas do sector "agricultura" se formule, con certa frecuencia, como simples

26 EEA, European Environment Agency (2014). Annual European Union greenhouse gas inventory 1990-2012 and inventory report 2014. European Environment Agency.

27 Ministry for the Environment (2014). New Zealand's Greenhouse Gas Inventory 1990 - 2012. Ministry for the Environment. April 2014.

http:/ / unfccc.int/ files/ national reports/annex i ghg inventories/ national inventories submissions Lapplication/zip/nzl-2014-nir-14apr.zip 
xeneralidades ou se formule sobre accións que terán a súa anotación contable fundamentalmente no sector enerxético.

No deseño de políticas de mitigación debemos ser conscientes da complexidade das medicións aos efectos de que o seu impacto sexa captado polo inventario nacional. A formulación de políticas e medidas débese basear non só no estudo concreto da medida, senón que debemos contemplar tamén as súas sinerxías e interaccións, pois, por exemplo, poderíamos deseñar unha medida que reduxera emisións nun aspecto pero que provocara maiores emisións noutro.

É evidente que tamén debemos ponderar o impacto de cada medida sobre o medio ambiente e a saúde humana e o "grao de madurez" das tecnoloxías a utilizar. Loxicamente esta tarefa debe ser asumida por equipos multidisciplinares e con axeitados coñecementos científico-técnicos. Non é sinxelo deseñar medidas de mitigación para este sector. O estar ao tanto das innovacións tecnolóxicas, postas ao servizo da redución de emisións, é unha das funcións dos deseñadores de medidas de redución que posteriormente deben ser postas ao alcance dos agricultores e gandeiros a un custo-eficiente. Os propoñentes de medidas de mitigación deben ter presente, que os agricultores e gandeiros, que serán os encargados de levalas á práctica, deberán á súa vez ser axudados mediante a posta en práctica de subsidios e axudas cando as medidas non sexan custo-eficientes. É moi conveniente ter presente que, en calquera sistema de produción, a rendibilidade é a miúdo o factor de decisión máis importante para determinar a adopción das diferentes prácticas de mitigación. Calquera práctica que requira un investimento engadido ou que poida diminuír a produtividade animal ou aumentar os custos de produción, probablemente será rexeitada polo agricultor ou gandeiro.

\section{Bibliografía}

AgriClimateChange (2014). Una agricultura respetuosa con el clima Evaluaciones energéticas y de emisiones de gases de efecto invernadero a escala de explotación en la Unión Europea. Proyecto LIFE. AgriClimateChange.

http:/ / www .agriclimatechange.eu/ index.php?option=com docman\&task=cat view\&gid $=5$ 2\&Itemid=79\&lang=es

CONAMA (2014). Mitigación y adaptación en el sector agrario. Coordina: Fundación Global Nature. Grupo de Trabajo 1. CONAMA. 2014.

http:/ / www .conama.org/ conama/ download/ files/ conama2014// GTs\%202014/ 1 final.p df

DG Climate Action. European Commission. (2012). Next phase of the European Climate Change Programme: Analysis of Member States actions to implement the Effort Sharing Decision and options for further community-wide measures. Agriculture sector - Policy case studies report. AEA DG ENV C.5/ SER/ 2009/ 0037. June 2012. DG Climate Action.

https:/ / www.google.es/ ?gws_rd=ssl\#q=AEA+DG+ENV+C.5\%2FSER\%2F2009\%2F0037.+J $\underline{\text { une }+2012}$

EEA, European Environment Agency (2014). Annual European Union greenhouse gas inventory 1990-2012 and inventory report 2014. European Environment Agency.

http:// www .eea.europa.eu/ publications/ european-union-greenhouse-gas-inventory$\underline{2014}$

European Parliament (2014). Measures at farm level to reduce greenhouse gas emissions from EU agriculture. Directorate general for internal policies. Policy department structural and cohesion policies. Agriculture and environmental development. European Parliament. 
http:/ / www .europarl.europa.eu/ RegData/ etudes/ note/join/ 2014/513997/IPOLAGRI NT\%282014\%29513997_EN.pdf

International Panel of Climate Change. UNEP.WMO.(1996). Revised 1996 IPCC Guidelines for National Greenhouse Gas Inventories. IPCC.

International Panel of Climate Change. UNEP.WMO (2006) Directrices del IPCC de 2006 para los inventarios nacionales de gases de efecto invernadero. IPCC.

Karin, Andeweg et al. (2014). Reducing greenhouse gas emissions from livestock: Best practice and emerging options The Livestock Research Group (LRG) of the Global Research Alliance on Agricultural Greenhouse Gases (GRA) and Sustainable Agriculture Initiative (SAI) Platform. New Zealand Agricultural Greenhouse Gas Research Centre (NZAGRC).

MAGRAMA (2014a). Encuesta sobre Superficies y Rendimientos de Cultivos en España, año 2013 (ESYRCE). MAGRAMA.

MAGRAMA (2014b). España, Informe Inventarios GEI 1990-2012 (Abril de 2014). MAGRAMA.

MAGRAMA (2014c). Inventarios Nacionales de Emisiones a la Atmósfera 1990-2012. Volumen 2: Análisis por Actividades SNAP. MAGRAMA.

Ministry for the Environment (2014). New Zealand's Greenhouse Gas Inventory 1990 2012. Ministry for the Environment. April 2014.

http:// unfccc.int/files/national reports/ annex i ghg inventories/national inventories su bmissions/application/zip/nzl-2014-nir-14apr.zip

Oficina Española de Cambio Climático (2014). Hoja de ruta de los sectores difusos a 2020. MAGRAMA. Oficina Española de Cambio Climático.

https:/ / www.google.es/ ?gws rd=ssl\#q=Oficina+Espa\%C3\%B1ola+de+Cambio+Clim\%C3 $\%$ A1tico+(2014).+Hoja+de+ruta+de+los+sectores+difusos+a+2020.+MAGRAMA.+Oficina +Espa\%C3\%B1ola+de+Cambio+Clim\%C3\%A1tico.

Parlamento Europeo y Consejo de la Unión Europea (2009). Decisión 406/2009/ CE del Parlamento Europeo y del Consejo de 23 de abril de 2009 sobre el esfuerzo de los Estados miembros para reducir sus emisiones de gases de efecto invernadero a fin de cumplir los compromisos adquiridos por la Comunidad hasta 2020.

Pierre J. Gerber et al. (2013). Mitigación de las emisiones de gases de efecto invernadero en la producción ganadera. Una revisión de las opciones técnicas para la reducción de las emisiones de gases diferentes al $\mathrm{CO}_{2}$. FAO,2013

https:// www.google.es/ ?gws rd=ssl\#q=Mitigaci\%C3\%B3n+de+las+emisiones+de+gases+ detefectotinvernaderoten+la tproducci\%C3\%B3n+ganadera.+Una+revisi\%C3\%B3n+de tlastopciones+t\% $\mathrm{C} 3 \% \mathrm{~A} 9 \mathrm{cnicas}+$ para + latreducci\% $\mathrm{C} 3 \% \mathrm{~B} 3 \mathrm{n}+$ de+lastemisiones+de+gases tdiferentes+al+CO2.+FAO+2013

Revista Galega de Economía: http:/ / www.usc.es/ econo/ RGE/ benvidag.htm Anexo on line: https:/ / ideas.repec.org/ s/ sdo/ regaec.html 